\title{
Pancreatic carcinoma development: new etiological and pathogenetic evidence
}

\author{
Sirio Fiorino, ${ }^{1}$ Letizia Bacchi-Reggiani, ${ }^{2}$ Laura Pontoriero, ${ }^{3}$ Claudio Gallo, ${ }^{4}$ Elisabetta Chili, ${ }^{5}$ Michele Masetti, ${ }^{6}$ \\ Nicola Zanini, ${ }^{6}$ Anna Grondona, ${ }^{7}$ Tania Silvestri, ${ }^{7}$ Gaia Deleonardi, ${ }^{7}$ Elisabetta Magrini, ${ }^{7}$ Roberto Motta, ${ }^{7}$ \\ Adele Fornelli, ${ }^{8}$ Arrigo Bondi, ${ }^{8}$ Dario De Biase, ${ }^{9}$ Paola Baccarini, ${ }^{9}$ Giovanni Tallini, ${ }^{9}$ Antonio Tropeano, ${ }^{10}$ \\ Andrea Cuppini, ${ }^{1}$ Gastone Castellani, ${ }^{11}{ }^{\text {Elio Jovine }}{ }^{6}$
}

${ }^{1}$ UO di Medicina Interna, Ospedale di Budrio, Budrio (BO); ${ }^{2}$ Istituto di Cardiologia, Policlinico S. Orsola-Malpighi, Università degli Studi di Bologna; ${ }^{3}$ UO Materno Infantile, Distretto Lametino, ASP, Catanzaro; ${ }^{4}$ Medico Specialista in Malattie Infettive; ${ }^{5} \mathrm{UO}$ di Anestesia e Rianimazione, Azienda Ospedaliera-Universitaria, Policlinico di Modena, Modena; ${ }^{6}$ UO di Chirurgia A, Ospedale Maggiore, Bologna; ${ }^{7}$ Laboratorio Centralizzato, Ospedale Maggiore, Bologna; ${ }^{8}$ Servizio di Anatomia Patologica, Ospedale Maggiore, Bologna; ${ }^{9}$ Servizio di Anatomia Patologica, Ospedale

Bellaria, Bologna; ${ }^{10}$ Specialista in Odontoiatria; ${ }^{11}$ Istituto di Fisica, Università degli Studi di Bologna, Italy

\begin{abstract}
Pancreatic adenocarcinoma (PAC) is a very aggressive cancer with a poor prognosis. To date, the causes and pathogenetic mechanisms involved in the development of this malignancy remain largely unknown. Therefore, additional studies are required to improve our knowledge of the events that occur during the process of pancreatic carcinogenesis. The purpose of this article is to describe the most recent evidence, concerning the possible risk factors and mechanisms that may contribute to determine the development of PAC, as well as models, such as the tensegrity model, that may explain this complex process. Available studies suggest that approximately $15-20 \%$ of human malignancies are somehow associated with chronic infection. Some epidemiological research has shown that some infectious agents represent risk factors for PAC. In particular, several reports showed that the infection caused by some micro-organisms, including helicobacter pylori and some bacterial species of oral microbiota, as well as by viral agents, such as human immunodeficiency virus (HIV), and hepatitis B (HBV) and C $(\mathrm{HCV})$ viruses, is associated with an increased probability of developing PAC. For the first time, observational studies and meta-analyses have suggested that HBV and HCV, two hepatotropic viruses with oncogenic properties, may be also risk factors for PAC. However, the small number of available reports, nearly all performed in Asian populations, limits their validity to these ethnic groups. Therefore, additional studies focusing on populations of different geographical areas and enrolling larger series of patients are required to confirm this association. Furthermore, an accurate description and a better understanding of the events and of the pathogenetic mechanisms involved in the process of pancreatic carcinogenesis, as proposed by the tensegrity model, might be a useful approach to effectively deal with this pathology.
\end{abstract}

Correspondence: Sirio Fiorino, UO di Medicina Interna, Ospedale Budrio, via Benni 44, 40065 Budrio (BO), Italy. Tel. +39.051.809259 - Fax: +39.051.809034.

E-mail: sirio.fiorino@ausl.bologna.it

Key words: pancreatic carcinoma, hepatitis B virus, hepatitis $\mathrm{C}$ virus, tensegrity, immune response.

Conflict of interests: the authors declare no potential conflicts of interest.

Acknowledgments: the authors thank Dr. Simonetta Righi, Biblioteca Centralizzata, Policlinico S. Orsola-Malpighi, Università di Bologna, Italy, for her support in the bibliographic search.

Received for publication: 13 February 2013.

Revision received: 28 March 2013.

Accepted for publication: 8 April 2013.

This work is licensed under a Creative Commons Attribution NonCommercial 3.0 License (CC BY-NC 3.0).

CCopyright S. Fiorino et al., 2013

Licensee PAGEPress, Italy

Italian Journal of Medicine 2013; 7:242-252

doi:10.4081/itjm.2013.242

\section{Introduction}

Pancreatic adenocarcinoma (PAC) represents a very aggressive and highly fatal malignancy, with an overall 5-year survival of less than $5 \% .{ }^{1}$ It is the $8^{\text {th }}$ most frequent cause of cancer-related death, and it causes approximately 250,000 deaths worldwide every year. ${ }^{2}$ The only treatment that may improve patients' survival is represented by a complete surgical resection with associated adjuvant chemo- or chemoradiotherapy. ${ }^{3-5}$ Unfortunately, although in recent years better diagnostic and therapeutic procedures have been introduced into clinical practice, current 5 -year survival after curative resection remains very low (approx. 15-20\%). ${ }^{6}$ Advanced stage at presentation, aggressive disease, early metastatic dissemination, absence of precocious symptoms and signs of disease, and lack of effective systemic therapies, 
make the diagnosis and treatment of this cancer very difficult. ${ }^{7}$ At the time of diagnosis, surgical resection with a curative intent is possible only in a minority of PAC patients. ${ }^{8}$

Therefore, there is a pressing need for research and development of new diagnostic and therapeutic approaches to improve the management and the poor prognosis of patients with this malignancy. Etiological factors and pathogenetic mechanisms involved in the process of carcinogenesis and, in particular, the causes of PAC development, are still largely unknown. In particular, only cigarette smoking ${ }^{9}$ and family history ${ }^{10}$ of this neoplasia are well-known risk factors for PAC. Furthermore, heavy fat intake in the diet, ${ }^{11}$ alcohol abuse, ${ }^{12}$ as well as history of diabetes mellitus ${ }^{13}$ and chronic pancreatitis ${ }^{14}$ have been associated with a higher incidence of PAC.

Evidence from various epidemiological and basic research studies suggests that approximately $15-20 \%$ of all human cancers are somehow linked to a persistent infection. In recent years, the potential role of some infectious agents, both bacteria and viruses, as risk factors for pancreatic carcinogenesis has been described with increasing frequency. In particular, with regards to bacteria-related infections, a recent meta-analysis, including six observational studies performed in the last decade, suggested that helicobacter pylori infection is associated with an increased risk of developing pancreatic cancer. ${ }^{15}$ It has already been demonstrated in the past that this bacterium is involved in the pathogenesis of peptic ulcer disease ${ }^{16}$ as well as of gastric carcinoma and lymphoma. ${ }^{17}$ Further studies suggested a possible link between oral pathologies, such as periodontitis, and enhanced risk of pancreatic cancer. ${ }^{18,19}$ There have also been reports of an association between variations in patients' oral microbiota (in particular, some species of salivary microorganisms, such as Neisseria Elongata, Streptococcus Mitis) and a higher incidence of pancreatic diseases, including neoplasia of this organ..$^{20}$ Nevertheless, it is still unclear whether oral flora has a causative or reactive role in carcinogenesis of pancreas.

In addition, some authors showed a significantly higher risk of PAC development in patients with HIV-related infection in comparison with the general population during highly active antiretroviral therapy, ${ }^{21,22}$ although other studies showed no increased incidence of this carcinoma in HIV-positive subjects undergoing this treatment. ${ }^{23}$ Several very recent epidemiological studies and meta-analyses have suggested that hepatitis B (HBV) and hepatitis C (HCV) virus, two hepatotropic viruses with well-known oncogenic properties may be risk factors not only for liver carcinoma, intrahepatic cholangiocarcinoma and for some forms of non-Hodgkin's lymphoma, but also for PAC. HBV and HCV persistent infections represent a serious public health problem worldwide, affecting approximately 400 and 180 million people, respectively. It is widely recognized that in the liver both viruses may cause a persistent local necroinflammatory disease, with different patterns of severity and disease course, and that antigens and replicative sequences of $\mathrm{HBV}$ and $\mathrm{HCV}$ have also been detected in different extra-hepatic tissues, including pancreas.

The aim of this paper is to report recent insights into the role of HBV and HCV in pancreatic carcinogenesis. Particular attention is focused on a description of the following issues: i) studies and recently published meta-analyses assessing the possible association between HBV or HCV and risk of pancreatic cancer; ii) new models concerning cytogenesis and histogenesis of this carcinoma. Early studies reported that PAC develops from cells of ductal epithelium. Nevertheless, more recent evidence suggests that at least a part of human and animal PAC may have an acinar/centroacinar origin or develop in specialized structures, the so-called gland-like mucinous outpouches of major ducts; iii) pancreatic microenvironment during development of cancer in this organ. The transition from normal pancreatic tissue to cancer is characterized by a dynamic network and cooperative interactions, occurring among cells with a progressively transformed phenotype, immune, endothelial, pancreatic stellate cells, extracellular stroma and modulating mediators, such as cytokines, inflammatory and growth factors; iv) the tensional integrity or tensegrity model. This refers to a key characteristic that all nucleated cells present, i.e. that they contain a special structure, known as the cytoskeleton, a molecular scaffold that generates tensile forces and distributes them to other cellular and extracellular components. Normal tissue function and cellular shape stability are maintained by regular and constant architectural connections, including cell-cell and cell-stroma adhesions. In this way, cells may control their architecture and form. It is well known that some important cellular functions, including cellular differentiation, apoptosis or growth, are modulated by cellular architecture and shape. Some experimental studies suggested that the deregulation of tissue structural context and of mechanical properties of cells and extracellular matrix causes changes in intracellular biochemistry and gene expression; therefore, these events may promote neoplastic transformation and tumor progression; v) a description of the available in vivo and in vitro studies of the immune system response against pancreatic cancer and, in particular, the possible role of T-regulatory (Tregs) cells during the process of carcinogenesis in this organ. 


\section{Possible role of hepatitis $B$ and $C$ virus as risk factors for pancreatic carcinoma}

Several studies showed that HBV- and HCV-related persistent infection is able to cause a necroinflammatory liver injury with different patterns of severity and course. Chronic hepatic damage, induced by both viruses, represents a high-risk condition for cirrhosis and hepatocellular carcinoma (HCC) development. On the other hand, even if clinical evidence suggests that HBV and HCV may infect pancreas and viral antigens, as well as the fact that replicative intermediate forms have been detected in pancreatic specimens, to date only a few studies investigating the role of both viruses as risk factors for pancreatic carcinogenesis in humans are available. There are several reasons for the small number of reports on this topic: i) difficulties in studying pancreas by means of modern imaging techniques or bioptic procedures, because of the anatomic localization of this organ in the retroperitoneal space; ii) the small size of the majority of precursor cancerous lesions that often prevents their detection at early stages; iii) life-cycle characteristics of both viruses, making it difficult to assess their role in human pathology; iv) ability of HBV and HCV to productively infect, in vitro, a narrow range of hepatic cellular lines and, in vivo, only humans and chimpanzees.

However, in recent years, this subject has been gradually gaining importance and some studies have already been conceived and completed or are still ongoing. It is now well-known that, in patients with persistent HBVand $\mathrm{HCV}$-infection, antigens and genome sequences of both viruses are detectable not only in liver, but also in extra-hepatic tissues. The first studies concerning this topic date back to 1980-1981 when hepatitis B surface antigen (HBsAg) was observed in pancreatic juice and bile of patients with both acute and chronic virus-related hepatitis, ${ }^{24,25}$ whereas HBsAg and hepatitis B core antigen $(\mathrm{HBcAg})$ were found in the cytoplasm of pancreatic acinar cells in individuals with different forms of hepatic damage on whom a post mortem examination was performed. ${ }^{26}$ In 1984, a study showed the presence of some integrated HBV-DNA sequences in pancreatic tissue of 2 patients who died of HBV-related liver diseases. ${ }^{27}$ In 1985, a retrospective study was performed on pancreatic specimens of 199 patients undergoing a surgical procedure and detected HBsAg in the pancreatic acinus epithelia and small ductules in 2 patients with chronic pancreatitis and in 5 subjects with pancreatic adenocarcinoma. ${ }^{28}$

It has been shown that $\mathrm{HCV}$ is also able to replicate in extra-hepatic sites. HCV antigen and its replicative forms have been observed in several organs, including lymph nodes, spleen, ovary, thyroid, uterus and pancreas. ${ }^{29-31}$ In spite of these initial observations, it is only in the last five years that epidemiological trials, includ- ing case/controls and prospective studies, have been performed to assess the possible association between previous or persistent HBV- or HCV-related infection and risk of pancreatic carcinoma. Most of these studies have been published between 2010 and 2012, and for the most part they were carried out in China. ${ }^{32-36}$ In September 2012, a systematic review of observational studies was published that focused on HBV/HCV status and risk of malignancy in pancreas. In this study, the authors hypothesized that pathogenetic mechanisms involved in HCC development might be common to pancreatic carcinogenesis. ${ }^{37}$

Subsequently, between the end of 2012 and the beginning of 2013, at least three meta-analyses have been published confirming that both viruses are risk factors for the development of pancreatic cancer. ${ }^{38-40}$

Further evidence supports the results of these epidemiological studies.

- Several in vitro studies demonstrated that some human hepatoma cells and pancreatic cancer cell lines were able to undergo a process of transdifferentiation into hepatocyte-like cells upon definite and well-standardized conditions of culture. ${ }^{41,42} \mathrm{~A}$ wide series of induction programs have been proposed, on the basis of different experimental conditions and objectives. In particular, upon treatment with dexamethasone and oncostatin $\mathrm{M}$, cellular lines from a pancreatic origin were able to trans-differentiate into permissive hepatocyte-like cells that were able to sustain HBV replication with production of viral antigens, replicative forms and entire genomes, when they were permanently transfected with HBVDNA. ${ }^{43}$ Chronic pancreatic damage might induce in this organ the transdifferentiation of some cells into hepatocyte-like cells, supporting HBV replication.

- On the basis of research on human and animal morphogenetic processes, liver and pancreas have in common many features during their embryological growth, arising from common multipotent cells of endoderm origin. ${ }^{44,45}$

- Some intracellular signaling paths, deregulated during pancreatic carcinogenesis, are similar to those perturbed in patients with chronic HBV or HCV infection with associated persistent hepatic inflammatory injury and HCC development. ${ }^{37}$

\section{Pancreatic carcinoma cytogenesis and histogenesis}

Available data suggest that, as reported in liver, development of pancreatic carcinoma results from a multistep process. ${ }^{46,47}$ Consensus to the nomenclature and classification system of human pancreatic cancer precursors and identification of related genome mutations substantially improved our understanding of this malignancy. ${ }^{48-50}$ It has been suggested that PAC develops 
from early lesions, such as pancreatic intraepithelial neoplasia (PanINs), mucinous cystic neoplasm and intraductal papillary-mucinous neoplasm. Among these pre-malignant conditions, PanINs are the best known. In particular, they are characterized by a wide spectrum of patterns, ranging from low- (PanIN-1A and 1B) to high-grade (PanINs-2 with dysplasia, PanINs-3 or carcinoma in situ, invasive cancer) lesions. However, although in the past a model of linear progression, from PanINs-1 to PanINs-3, has been proposed to explain how pancreatic cancer develops, no definite demonstration has been obtained to validate this paradigm. The sequence of steps, starting from pre-neoplastic lesions and leading to invasive malignancy, might follow a different course. ${ }^{51-54}$ It has to be emphasized that neither the cells from which pancreatic carcinoma originates, nor its histogenesis, are completely understood, and no univocal conclusions have yet been obtained. Early research reported that this cancer arises from cells of epithelial duct. Nevertheless, recent studies report that at least a part of pancreatic carcinoma may originate from acinar or centro-acinar cells or develop in specialized pancreatic compartments, represented by the gland-like mucinous outpouches of major ducts. ${ }^{55,56}$ In particular, available experimental evidence seems to suggest that, in a context of persistent inflammation in pancreatic tissue, a process characterized by acinar-to-ductal mucinous metaplasia may occur. Furthermore, in this organ, human acinar cells adjacent to areas of cancer present ductal markers. ${ }^{57}$ Metaplasia is a condition linked to an increased risk of cancer, because it induces a permissive setting where several pro-oncogenetic factors may be expressed. ${ }^{58}$ As a consequence of tissue damage, restoration of its normal structure is the consequence of a resultant regenerative process. Metaplasia is characterized by the substitution of one cell type with another. In particular, different mechanisms may be involved, such as selective replacement or expansion of cellular subsets, differentiation of progenitor cells, as well as transdifferentiation. This process is characterized by the transition between different types of differentiated cells.

\section{Pancreatic microenvironment and carcinogenesis: tensional integrity or tensegrity model}

A progressive transformation from normal tissue to acinar-ductal metaplasia and to invasive cancer characterizes pancreatic carcinogenesis. A reciprocal interplay occurs among cells that are, step by step, acquiring a neoplastic phenotype and the adjacent stroma. Malignant cells release growth factors that, via paracrine and/or autocrine pathways, are able to modify and remodel surrounding connective tissue, promoting a supportive microenvironment for cancer initiation and growth.
Several cellular types, such as neoplastic, immune (macrophages, neutrophils, dendritic cells, effector and regulatory lymphocytes), pancreatic stellate, endothelial, bone-marrow derived cells, as well as modulating factors, including interleukins, cytokines, growth and inflammatory factors, contribute to this complex process. A dynamic crosstalk develops in this microenvironment where malignant and stromal cells interact and activate one another. One of the effects of this interplay is represented by the progressive deposition of a modified extracellular matrix (ECM) which surrounds cancer cells and includes collagen type I, III, V, fibrinogen, fibronectin. This tissue consists of a dense abnormal stroma, called desmoplasia, which is characterized by an increased stiffness. ${ }^{59-61}$

Several mediators and cellular signaling pathways are involved in cancer initiation, progression and growth, inducing a process of inflammation and neovascularization in local tissue. ${ }^{62,63}$

Cancer is a disease characterized by a deep deregulation of mechanisms, controlling organization of both cells inside the tissues and tissues within organs. ${ }^{64} \mathrm{Un}$ controlled cellular growth is a necessary but not sufficient condition for cancer development. Neoplastic transformation of a tissue is characterized by an autonomous cellular proliferation, associated with a progressive disorganization of its normal structure as well as with the possibility of generating metastases. But a key event in this process is represented by the breakdown of proper epithelial-mesenchymal interactions. Several points have to be considered.

- Cellular shape is able to influence and modulate a large series of cellular activities, such as growth, differentiation, apoptosis, motility and ability to adhere to basal membrane and to tissue ECM. ${ }^{65}$

- Cytoskeleton is the most important mechanical component of the cells. It includes three major interconnected elements: microfilaments, intermediate filaments and microtubules. On the basis of different intracellular organization and context, these structures may have a dual role and exert compression or tension. In particular, within cells, tensional forces generated by microfilaments and intermediate filaments are counteracted and balanced by forces, resisting compression, which are originated by microtubules and extracellular matrix adhesions. ${ }^{66}$

- Within cells, tensional forces generated by microfilaments and intermediate filaments are counteracted and balanced by forces, resisting compression, which are derived from microtubules and extracellular matrix adhesions. Therefore, the cytoskeleton represents a dynamic scaffold that controls cellular stability and actively contributes to determine cellular shape. Furthermore, each cell must not be considered as a structure apart, but it is connected with 
adjacent cells and with neighboring ECM either directly or by means of a basal membrane (BM). As a whole, these different tissue components constitute a single and intricate, but perfectly integrated, framework. ${ }^{64}$

In order to explain the balance between intracellular and extracellular forces, several years ago, Donald Ingber suggested the application of a tensional integrity or tensegrity model. Therefore, mechanical loads act as developmental regulators. ${ }^{67,68}$ According to this model, cells may be considered as tensed structures that are resistant to shape distortion and that self stabilize by encompassing other supportive structures that counteract compression. Furthermore, cytoskeleton is directly associated with integrins, which represent specialized mechanoreceptors on the cellular surface. They are able to sense mechanical signals that are applied to cells and to react against them, generating different types of response, such as an increase in cytoskeletal tension. Mechanical distortion of cells, via integrin receptor system, results in alteration of cytoskeleton as well as of ECM. On the other hand, an increase in the exogenous tension (matrix rigidity or stiffness) produces also dramatic effects on intracellular signaling, on matrix adhesion, as well as in endogenous tension (contractility). On the whole, also these events may influence cellular fate, by switching cells among different states critical for cancer development, such as proliferation, apoptosis, differentiation and motility. Mechanical forces might act as regulators of cell and tissue development. Cytoskeleton represents a framework which controls and influences motility and function of intracellular organelles as well as proper activity and orientation of enzymes and substrates, with a key role in critical biochemical reactions within cells. ${ }^{69}$ Some experimental studies suggest that perturbation of tissue structure, as well as alteration of cellular and ECM mechanical properties, cause modifications of multiple intracellular signaling pathways. The final effect of these events is represented by a substantial change in intracellular biochemical activity and genome expression. ${ }^{70}$ For example, collective interactions occurring in an epithelial tissue among cytoskeletal structures mediate the adhesion of each cell to BM, influencing its form and modulating intracellular transduction of mechanical forces applied to tissue. ${ }^{71}$

\section{Dynamics of immune response during the development of pancreatic cancer in animal models}

A complete analysis of inflammatory response and desmoplastic reaction, involved in early as well as in more advanced phases of pancreatic carcinogenesis, has been possible only in animal models. A recent study assessed in vivo the dynamics of immune system activity during this process. In particular, the events that occur in pancreas during appearance and growth of this cancer have been reproduced in a genetically engineered mouse model that summarizes clinical, molecular and histological characteristics of this malignancy during its development from precursor lesions to invasive tumor. ${ }^{55,72}$

According to this model, several steps characterize the initiation and progression of this cancer, including: i) a progressive inflow of fibroblasts, stromal cells and leukocytes, gradually surrounding precursor lesions, during PanINs development; ii) production and release of an altered ECM, rich in collagen component, with characteristics similar to desmoplastic reaction detectable in cancer of pancreas. This process is modulated by pancreatic stellate cells (PSCs).

As a result of an acute or chronic injury in this organ, they become active and acquire a fibroblastlike phenotype. The most important features of activated PSCs include: vitamin A droplet loss, increase of mitotic index, alfa-smooth muscle actin production, enhanced motility and contractility. ${ }^{73,74}$ Pancreatic tissue is infiltrated by immune cells, which, on cellular surface, present leukocyte common antigen 45 (CD45). They progressively increase during development and progression of this malignancy. In peritumoral stroma, a small number of $\mathrm{CD}^{+}$and $\mathrm{CD} 8^{+} \mathrm{T}$ lymphocytes with anti-cancer effector properties is detectable in the early phases of the neoplastic process and these subsets do not posses activation markers. In advanced stages, an increased number of $\mathrm{T}$ lymphocytes infiltrating pancreatic tissue are observed, but these cells exhibit poor or no protection against cancer cells. A significant inflow of immune cells with immunosuppressive activities may be already observed in the early stage of pancreatic carcinogenesis. Phenotypic assessment of these immune cells shows that stromal tissue adjacent to precursor and invasive lesions is rich in Tregs cells, tumor-associated macrophages and myeloid suppressor cells.

\section{Immune response in patients with pancreatic carcinoma: role of T-regulatory cells}

In recent years, a large series of studies focused on how the immune system may counteract tumor promotion, initiation and progression. It is now recognized that the immune system presents a dual role in cancer: it may inhibit the growth of malignancies, by suppressing proliferation of neoplastic cells or by destroying them, and it may promote a microenvironment facilitating the establishment and the persistence of cancer by selecting clones of malignant cells that are more likely to survive in an immunocomponent host. Several immunological mechanisms seem to play a crucial role in the control and suppression of 
tumor development. Different subclasses of immune cells, including in particular cytotoxic $\mathrm{CD} 8 \mathrm{~T}^{+}$lymphocytes (CTLs), CD4 T cells with helper functions and natural killer cells, are involved in the immune response against tumor and their activity is subject to a fine and tight regulation. ${ }^{75,76}$ The tumors are often characterized by infiltrates of immune cells with an inflammatory phenotype. ${ }^{77,78}$ The accumulation of these cells is the result of an interaction between the immune system and the tumor during its development and growth. ${ }^{79}$ The size and the composition of these infiltrates vary considerably according to the type, grade and stage of the malignancies, and their presence confirms that the host immune system develops a response against tumor. This process is called immune surveillance. ${ }^{80}$ Although in the past some clinical studies showed that survival of patients with different kinds of cancer is improved by the presence of cancer-infiltrating cells, ${ }^{81,82}$ in recent years, available research reports that the type, density, and location of immune cells within neoplastic tissue predicts clinical outcome and prognosis. ${ }^{83-85}$

In particular, it has been suggested that the presence of intratumoral $\mathrm{T}$ lymphocytes with an effector phenotype has a favorable impact on the prognosis of patients with hepatic, ${ }^{86,87}$ colorectal $^{88,89}$ and ovarian carcinoma. ${ }^{90}$ Although it is well-known that many malignancies present modified antigens able to stimulate cytotoxic T-cell responses, immune system activity is generally weak and unable to block neoplastic proliferation. ${ }^{91}$ This situation is characterized by the ability of the cancer microenvironment to inactivate or decrease the functionality of effector cells of the immune system with anti-tumor properties and to induce a condition of immune tolerance.

Several mechanisms have been proposed to explain the reduced response of the immune system against cancer: partial antigenic masking, deregulation of antigenic processing events, inadequate co-stimulation or direct suppression of effector cells. ${ }^{92}$ Therefore, a dynamic and self-maintaining interplay is generated through which immune cells affect the neoplastic microenvironment and are, in turn, influenced by it. ${ }^{93}$ The final effect of this process is represented by the progressive weakening of the protective immune response and by the associated increase in cancer growth and progression.

In recent years, in the heterogeneous population of $\mathrm{CD}^{+} \mathrm{T}$ cells, a subset of specialized $\mathrm{CD} 4^{+} / \mathrm{CD} 25^{+} \mathrm{T}$ lymphocytes with constitutive or induced regulatory immunosuppressive function (Tregs) has been identified and characterized. These T cells control the function of $\mathrm{CD}^{+}$and $\mathrm{CD}^{+}$effector cells, which exert cytotoxic and helper activities during the protective phase of immune response, modulating their proliferation and cytokine release. Therefore, Treg cells, that help to prevent the development of organ-specific autoimmune diseases, play an essential role in the preservation and in the maintenance of host homeostasis and self-tolerance. ${ }^{88,89}$

Several studies showed that Treg cell dysfunction is involved in the pathogenesis of several diseases, such as inflammatory bowel diseases, autoimmune hepatitis, HBV- and HCV-related chronic hepatitis, thyroiditis and, probably, malignancies. The population of Treg cells is heterogeneous and it includes lymphocytes with extremely intricate patterns of cellular surface receptors and of cytokine production. Briefly, according to experimental evidence, Treg lymphocytes may be subdivided into two categories: induced (iTreg) or natural (nTreg) Treg cells. The latter population represents approximately $5-10 \%$ of $\mathrm{CD}^{+}$subsets. It originates in the thymus and is characterized by constitutive expression of a CD4 CD2 $5^{\text {high }}$ Foxp3 positive pattern and by suppressive properties against $\mathrm{CD}^{+}$and $\mathrm{CD} 8^{+}$T-effector lymphocytes. ${ }^{94,95}$ It has been reported that Foxp 3 transcription factor modulates development and differentiation of Treg cells, ${ }^{96,97}$ therefore, it is considered a specific marker of this population. On the other hand, iTreg subsets are able to proliferate in peripheral tissues in response to antigenic stimulation and they may originate from circulating naïve $\mathrm{CD}^{+} \mathrm{T}$ lymphocytes in the presence of appropriate stimuli, such as entity, duration and modality of antigenic presentation, as well as type of microenvironment, where these cells and antigens engage. The activities of some interleukins, including IL-2, IL-10 and transforming growth factor (TGF- $\beta$ ) seems to promote a Treg phenotype in $\mathrm{CD} 4^{+} \mathrm{CD} 25^{-}$ Foxp3- naïve T populations. ${ }^{98,99}$ Both Treg cells and several subsets of $\mathrm{T}$ lymphocytes with effector properties share CD4 and CD 25 receptors on their cellular surface and this makes it difficult to distinguish these different populations. Furthermore, other receptors such as glucocorticoid-induced tumor necrosis receptor and intracellular antigen- 4 associated with cytotoxic $\mathrm{T}$ lymphocytes were proved not to be useful markers to identify Treg cells.

Fox $3 p$ itself may be transiently expressed on cellular surface of some effector $\mathrm{T}$ subsets as a result of their activation, and its intracellular localization makes it very hard to recognize Treg populations. ${ }^{100-102}$ Therefore, some studies by several authors have attempted to identify specific receptor patterns, and to reliably characterize effector and regulatory $\mathrm{T}$ cells. Recently, CD 127, representing the $\alpha$-chain for IL-7 receptor, has been proposed as a very useful marker to distinguish these different populations. According to available evidence, Treg cells seem to express low titers of CD127 (Treg127 low), whereas it has been reported that $\mathrm{T}$ lymphocytes with protective activities against pathogens or malignant cells exhibit high levels of this 
marker ( T CD127 $7^{\text {high }}$. ${ }^{103,104}$ However, elevated values of CD127 are detectable only on T-effector cells with a memory phenotype after engagement with specific antigen and the subsequent differentiation process. ${ }^{105}$

Prevalence of Treg cells is increased in peripheral blood of patients with different types of neoplasias, including liver, ${ }^{106}$ colorectal,,${ }^{107}$ breast, ${ }^{108}$ esophageal, and gastric carcinoma ${ }^{109}$ compared to healthy subjects. An early enhancement of Treg subsets occurs also in neoplastic tissue, as reported in pre-malignant lesions $^{81,110}$ and the percentage of Treg populations increases, depending on cancer stage and presence of metastases. ${ }^{111,112}$ The detection of Treg cells infiltrating regional lymph nodes adjacent to tumor also predicts an unfavorable outcome, as suggested by a study performed in women with ovarian carcinoma. ${ }^{113}$ Even in patients with pancreatic cancer, a specific interaction between host neoplastic and immune cells has been observed. In particular, it has been reported that Treg subsets exert strong immune-suppressive activities against $\mathrm{CD}^{+}$cytotoxic as well as $\mathrm{CD} 4^{+}$helper lymphocytes, possessing specific anti-cancer function.

Ikemoto showed a significant enhancement of $\mathrm{CD}^{+} \mathrm{Foxp}^{+}{ }^{+} \mathrm{T}$-cell population in peripheral blood of patients with pancreatic carcinoma in comparison with healthy donors and that percentage of Treg subsets correlates with TNM stage. ${ }^{114}$ On the other hand, Hiraoka reported that the prevalence of $\mathrm{CD}^{+} \mathrm{Foxp}^{+} \mathrm{T}$ cells, infiltrating pancreatic cancer tissue and regional lymph nodes, increases during the progression of this tumor, ranging from precursor lesions, such as PanINs and intraductal-papillary mucinous neoplasia, to invasive carcinoma. A high prevalence of these Treg subsets predicts a poor prognosis. ${ }^{115}$ Hinz suggested a novel mechanism of immune evasion in pancreatic carcinoma. To date, ectopic expression of Foxp3 has been detected in neoplastic tissue collected from patients suffering from this type of malignancy. These results show that pancreatic cancer and Treg cells share pathogenetic mechanisms. Therefore, neoplastic cells may mimic the function of Treg subsets, suppressing immune system activity and promoting tumor growth. ${ }^{116}$

In infection/inflammation/cancer models, a preferential migration of Treg cells into pathological areas is regulated and modulated by expression of specific receptors and chemokines. ${ }^{117-119}$

Several important homing receptors have been identified, such as chemokine receptors 4, 5, 6, 7 and 8 (CCR4, CCR5, CCR6, CCR7 and CCR8). ${ }^{120-124}$ They promote an efficient migration of Treg cells into sites where inflammatory or malignant processes are developing. It has been reported that, in murine and human cancers of pancreas, Treg lymphocytes detectable in neoplastic tissue exhibit CCR5 receptor and that tumor cells themselves produce ligands specific for CCR5, such as chemokine ligand 5 (CCL5). In a murine model, a reduced expression of CCL5 by pancreatic cancer cells reduces the ability of Treg lymphocytes to migrate into cancer tissues and, as a consequence, it induces a slowdown in tumor growth. ${ }^{125}$

\section{Conclusions}

Recent studies are improving our knowledge on the risk factors and pathogenetic mechanisms involved in PAC development. For the first time, epidemiological research has shown that infectious pathogens, such as viruses, may have a role in pancreatic carcinogenesis, although the small number of available reports, nearly all performed in Asian populations, limits their validity to these ethnic groups and their results should be interpreted with caution. Therefore, further studies focusing on populations of different geographical areas and involving larger series of patients are required to confirm this association. It should be considered that, in Asian countries such as China, $\mathrm{HBsAg}$ and $\mathrm{HBcAb}$ positivity is the most frequent serum pattern in $\mathrm{HBV}$-infected patients, whereas in Western nations, HBsAb positive/ $\mathrm{HBcAb}$ positive or $\mathrm{HBsAb}$ negative/ $\mathrm{HBcAb}$ positive antibody profiles are widespread in the population, because HBV mass vaccination has greatly reduced the incidence of HBsAg positivity. Unfortunately, it is not known if $\mathrm{HBsAb}$ positive/ $\mathrm{HBcAb}$ positive or $\mathrm{HBsAb}$ negative/HBcAb positive status are associated with an increased probability of pancreatic cancer. To date, only three studies have evaluated the risk of development of pancreatic carcinoma in these subjects and two of these suggested a higher incidence of pancreatic cancer in individuals with $\mathrm{HBsAg}$ negative/HBcAb positive/ $\mathrm{HBs} A b$ negative pattern in comparison with controls. ${ }^{11,35}$ Therefore, this antibody profile, which is generally considered to be a sign of previous and recovered $\mathrm{HBV}$ infection, might have clinical importance. So far, no definitive conclusions may be drawn. However, should a causal role of $\mathrm{HBV} / \mathrm{HCV}$ in the promotion of pancreatic carcinogenesis be definitively confirmed in further well-designed and well-adjusted studies, screening programs might be justified in patients with active or previous hepatitis $\mathrm{B}$ and $\mathrm{C}$ viral infection, although for the moment these programs are not feasible given the methods currently available and their high costs. Furthermore, in recent years, our understanding of PAC pathogenesis, such as processes of cytogenesis and histogenesis, immune system activities against this cancer, as well as the dynamic network and cooperative interactions occurring in the pancreatic microenvironment among cancer, immune, endothelial, pancreatic stellate cells and modulating factors has considerably 
increased. Unfortunately, for the moment, in spite of these apparently encouraging results, the prognosis of this malignancy is still very poor and its treatment has not substantially improved. Therefore, additional efforts are needed to increase our knowledge of the molecular events as well as of macroscopic and microscopic tissue modifications, detectable during initiation and progression of pancreatic carcinoma. The development of models that describe the possible steps involved in the early phases of cancer presentation, as well as in its progression, might be a very useful approach to effectively deal with this pathology. In particular, the tensegrity model, proposed by Donald Ingber, has provided convincing hypotheses on possible mechanisms occurring during the general process of carcinogenesis. Therefore, it might be time to take a step forward and to apply the principles of this experimental model to clinical practice. A similar approach might considerably improve our understanding of the pathogenetic mechanisms involved not only in carcinogenesis of pancreas, but also of other organs. This new study and investigation approach might provide an important advance in the diagnosis and treatment of PAC, and it might have a considerable impact on the comprehensive management of patients affected by this aggressive malignancy.

\section{References}

1. Jemal A, Siegel R, Ward E, et al. Cancer statistics, 2007. CA Cancer J Clin 2007;57:43-66.

2. Parkin DM, Bray F, Ferlay J, Pisani P. Global cancer statistics, 2002. CA Cancer J Clin 2005;55:74-108.

3. Imamura M, Doi R, Imaizumi T, et al. A randomized multicenter trial comparing resection and radiochemotherapy for resectable locally invasive pancreatic cancer. Surgery 2004;136:1003-11.

4. Gouma DJ, van Geenen RC, van Gulik TM, et al. Rates of complications and death after pancreaticoduodenectomy: risk factors and the impact of hospital volume. Ann Surg 2000;232:786-95.

5. Schnelldorfer T, Ware AL, Sarr MG, et al. Long-term survival after pancreatoduodenectomy for pancreatic adenocarcinoma: is cure possible? Ann Surg 2008;247: 456-62.

6. Oettle H, Post S, Neuhaus P, et al. Adjuvant chemotherapy with gemcitabine vs observation in patients undergoing curative-intent resection of pancreatic cancer: a randomized controlled trial. JAMA 2007;297:267-77.

7. Esposito I, Kleeff J, Bergmann F, et al. Most pancreatic cancer resections are R1 resections. Ann Surg Oncol 2008; 15:1651-60.

8. Kleeff J, Reiser C, Hinz U, et al. Surgery for recurrent pancreatic ductal adenocarcinoma. Ann Surg 2007;245: 566-72.

9. Hidalgo M. Pancreatic cancer. N Engl J Med 2010;362:1605-17.

10. Jacobs EJ, Rodriguez C, Newton CC, et al. Family history of various cancers and pancreatic cancer mortality in a large cohort. Cancer Causes Control 2009;20:1261-9.

11. Hassan MM, Bondy ML, Wolff RA, et al. Risk factors for pancreatic cancer: case-control study. Am J Gastroenterol 2007;102:2696-707.

12. Apte M, Pirola R, Wilson J. New insights into alcoholic pancreatitis and pancreatic cancer. J Gastroenterol Hepatol 2009;24:S51-6.

13. Chari ST, Leibson CL, Rabe KG, et al. Pancreatic cancer-associated diabetes mellitus: prevalence and temporal association with diagnosis of cancer. Gastroenterology 2008;134:95-101.

14. Lowenfels AB, Maisonneuve P, Lankisch PG. Chronic pancreatitis and other risk factors for pancreatic cancer. Gastroenterol Clin North Am 1999;28:673-85.

15. Trikudanathan G, Philip A, Dasanu CA, Baker WL. Association between Helicobacter pylori infection and pancreatic cancer. A cumulative meta-analysis. J Pancreas 2011;12:26-31.

16. Marshall BJ. Helicobacter pylori. Am J Gastroenterol 1994;89:S116-28.

17. Correa P, Houghton J. Carcinogenesis of Helicobacter pylori. Gastroeneterology 2007;133:659-72.

18. Michaud DS, Joshipura K, Giovannucci E, Fuchs CS. A prospective study of periodontal disease and pancreatic cancer in US male health professionals. J Natl Cancer Inst 2007;99:171-5.

19. Stolzenberg-Solomon RZ, Dodd KW, et al. Tooth loss, pancreatic cancer and Helicobacter pylori. Am J Clin Nutr 2003;78:176-81.

20. Farrell JJ, Zhang L, Zhou H, et al. Variations of oral microbiota are associated with pancreatic diseases including pancreatic cancer. Gut 2012;61:582-8.

21. Serraino D, Dal Maso L, De Paoli A, et al. On changes in cancer mortality among HIV-infected patients: is there an excess risk of death from pancreatic cancer? Clin Infect Dis 2009;49:481-2.

22. Engels EA, Biggar RJ, Hall HI, et al. Cancer risk in people infected with human immunodeficiency virus in the United States. Int J Cancer 2008;123:187-94.

23. Simard EP, Pfeiffer RM, Engels EA. Spectrum of cancer risk late after AIDS onset in the United States. Arch Intern Med 2010;170:1337-45.

24. Hoefs JC, Renner IG, Askhcavai M, Redeker AG. Hepatitis B surface antigen in pancreatic and biliary secretions. Gastroenterology 1980;79:191-4.

25. Redeker AG, Hoefs JC, Renner IG, Ashcavai M. Does hepatitis B virus grow outside the liver. Gastroenterology 1980;79:600.

26. Shimoda T, Shikata T, Karasawa T, et al. Light microscopic localization of hepatitis B virus antigens in the human pancreas. Possibility of multiplication of hepatitis $\mathrm{B}$ virus in the human pancreas. Gastroenterology 1981;81:998-1005.

27. Dejean A, Lugassy C, Zafrani S, et al. Detection of hepatitis B virus DNA in pancreas, kidney and skin of two human carriers of the virus. J Gen Virol 1984;65:651-5.

28. Hohenberger P. The pancreas as target organ for hepatitis B virus-immunohistological detection of HBsAg in pancreatic carcinoma and chronic pancreatitis. Leber Magen Darm 1985;15:58-63.

29. Laskus T, Radkowski M, Wang LF, et al. Search for hepatitis $\mathrm{C}$ virus extrahepatic replication sites in patients 
with acquired immunodeficiency syndrome: specific detection of negative-strand viral RNA in various tissues. Hepatology 1998;28:1398-401.

30. Sugiyama K, Kato N, Ikeda M, et al. Hepatitis C virus in pelvic lymph nodes and female reproductive organs. Jpn J Cancer Res 1997;88:925-7.

31. Chen MY, Huang ZQ, Chen LZ, et al. Detection of hepatitis $\mathrm{C}$ virus NS5 protein and genome in Chinese carcinoma of the extrahepatic bile duct and its significance. World J Gastroenterol 2000;6:800-4.

32. Hassan MM, Li D, El-Deeb AS, et al. Association between hepatitis B virus and pancreatic cancer. J Clin Oncol 2008;26:4557-62.

33. Iloeje UH, Yang HI, Jen CL, et al. Risk of pancreatic cancer in chronic hepatitis B virus infection: data from the REVEAL-HBV cohort study. Liver Int 2010;30: 423-9.

34. Wang DS, Chen DL, Ren C, et al. ABO blood group, hepatitis $\mathrm{B}$ viral infection and risk of pancreatic cancer. Int J Cancer 2012;131:461-8.

35. Ben Q, Li Z, Liu C, et al. Hepatitis B virus status and risk of pancreatic ductal adenocarcinoma: a case-control study from China. Pancreas 2012;41:435-40.

36. El-Serag HB, Engels EA, Landgren O, et al. Risk of hepatobiliary and pancreatic cancers after hepatitis $\mathrm{C}$ virus infection: A population-based study of U.S. veterans. Hepatology 2009;49:116-23.

37. Fiorino S, Lorenzini S, Masetti M, et al. Hepatitis B and $\mathrm{C}$ virus infections as possible risk factor for pancreatic adenocarcinoma. Med Hypotheses 2012;79:678-97.

38. Wang Y, Yang S, Song F, et al. Hepatitis B virus status and the risk of pancreatic cancer: a meta-analysis. Eur J Cancer Prev 2012. [Epub ahead of print].

39. Luo G, Hao NB, Hu CJ, et al. HBV infection increases the risk of pancreatic cancer: a meta-analysis. Cancer Causes Control 2013. [Epub ahead of print].

40. Fiorino S, Chili E, Bacchi-Reggiani L, et al. Association between hepatitis $\mathrm{B}$ or hepatitis $\mathrm{C}$ virus infection and risk of pancreatic adenocarcinoma development: A systematic review and meta-analysis. Pancreatology 2013. [Epub ahead of print].

41. Shen CN, Slack JM, Tosh D. Molecular basis of transdifferentiation of pancreas to liver. Nat Cell Biol 2000;2:879-87.

42. Cerec V, Glaise D, Garnier D, et al. Transdifferentiation of hepatocyte-like cells from the human hepatoma HepaRG cell line through bipotent progenitor. Hepatology 2007;45:957-67.

43. Wang RY, Shen CN, Lin MH, et al. Hepatocyte-like cells transdifferentiated from a pancreatic origin can support replication of hepatitis B virus. J Virol 2005;79:13116-28.

44. Zaret KS. Genetic programming of liver and pancreas progenitors: lessons for stem-cell differentiation. Nat Rev Genet 2008;9:329-40.

45. Wandzioch E, Zaret KS. Dynamic signaling network for the specification of embryonic pancreas and liver progenitors. Science 2009;324:1707-10.

46. Hingorani SR, Petricoin EF, Maitra A, et al. Preinvasive and invasive ductal pancreatic cancer and its early detection in the mouse. Cancer Cell 2003;4:437-50.

47. Tuveson DA, Shaw AT, Willis NA, et al. Endogenous oncogenic K-ras(G12D) stimulates proliferation and widespread neoplastic and developmental defects. Cancer Cell 2004;5:375-87.

48. Hruban RH, Adsay NV, Albores-Saavedra J, et al. Pancreatic intraepithelial neoplasia: a new nomenclature and classification system for pancreatic duct lesions. Am J Surg Pathol 2001;25:579-86.

49. Maitra A, Fukushima N, Takaori K, Hruban RH. Precursors to invasive pancreatic cancer. Adv Anat Pathol 2005;12:81-91.

50. Sipos B, Frank S, Gress T, et al. Pancreatic intraepithelial neoplasia revisited and updated. Pancreatology 2009;9:45-54.

51. Real FX. A "catastrophic hypothesis" for pancreas cancer progression. Gastroenterology 2003;124:1958-64.

52. Rooman I, Real FX. Pancreatic ductal adenocarcinoma and acinar cells: a matter of differentiation and development? Gut 2012;61:449-58.

53. Hruban RH, Takaori K, Klimstra DS, et al. An illustrated consensus on the classification of pancreatic intraepithelial neoplasia and intraductal papillary mucinous neoplasms. Am J Surg Pathol 2004;28:977-87.

54. Singh M, Maitra A. Precursor lesions of pancreatic cancer: molecular pathology and clinical implications. Pancreatology 2007;7:9-19.

55. Jamieson JD. Prospectives for cell and organ culture systems in the study of pancreatic carcinoma. J Surg Oncol 1975;7:139-41.

56. Habbe N, Shi G, Meguid RA, et al. Spontaneous induction of murine pancreatic intraepithelial neoplasia $(\mathrm{mPanIN})$ by acinar cell targeting of oncogenic Kras in adult mice. Proc Natl Acad Sci U S A 2008;105:18913-8.

57. Parsa I, Longnecker DS, Scarpelli DG, et al. Ductal metaplasia of human exocrine pancreas and its association with carcinoma. Cancer Res 1985;45:1285-90.

58. Reichert M, Rustgi AK. Pancreatic ductal cells in development, regeneration, and neoplasia. J Clin Invest 2011;121:4572-8.

59. Mahadevan D, Von Hoff DD. Tumor-stroma interactions in pancreatic ductal adenocarcinoma. Mol Cancer Ther 2007;6:1186-97.

60. Luo G, Long J, Zhang B, et al. Stroma and pancreatic ductal adenocarcinoma: an interaction loop. Biochim Biophys Acta 2012;1826:170-8

61. Imamura T, Iguchi H, Manabe T, et al. Quantitative analysis of collagen and collagen subtypes I, III, and V in human pancreatic cancer, tumor-associated chronic pancreatitis, and alcoholic chronic pancreatitis. Pancreas 1995;11:357-64.

62. Ji B, Tsou L, Wang H, Gaiser S, et al. Ras activity levels control the development of pancreatic diseases. Gastroenterology 2009;137:1072-82.

63. Truty MJ, Urrutia R. Basics of TGF-beta and pancreatic cancer. Pancreatology 2007;7:423-35.

64. Ingber DE. Cancer as a disease of epithelial-mesenchymal interactions and extracellular matrix regulation. Differentiation 2002;70:547-60.

65. Nelson WJ. Regulation of cell-cell adhesion by the cadherin-catenin complex. Biochem Soc Trans 2008;36: 149-55.

66. Fey EG, Wan KM, Penman S. Epithelial cytoskeletal framework and nuclear matrix-intermediate filament scaffold: three-dimensional organization and protein composition. J Cell Biol 1984;98:1973-84. 
67. Ingber DE. Mechanobiology and diseases of mechanotransduction. Ann Med 2003;35:564-77.

68. Ingber DE. Tensegrity-based mechanosensing from macro to micro. Prog Biophys Mol Biol 2008;97: 163-79.

69. Ingber DE. Tensegrity I. Cell structure and hierarchical systems biology. J Cell Sci 2003;116:1157-73.

70. Ingber D. Integrins as mechanochemical transducers. Curr Opin Cell Biol 1991;3:841-8.

71. Ingber DE. Cellular mechanotransduction: putting all the pieces together again. FASEB J 2006;20:811-27.

72. Clark CE, Hingorani SR, Mick R, et al. Dynamics of the immune reaction to pancreatic cancer from inception to invasion. Cancer Res 2007;67:9518-27.

73. Buchholz M, Kestler HA, Holzmann K, et al. Transcriptome analysis of human hepatic and pancreatic stellate cells: organ-specific variations of a common transcriptional phenotype. J Mol Med (Berl) 2005;83:795-805.

74. Erkan M, Weis N, Pan Z, et al. Organ-, inflammationand cancer specific transcriptional fingerprints of pancreatic and hepatic stellate cells. Mol Cancer 2010;9:88.

75. Fu J, Xu D, Liu Z, et al. Increased regulatory T cells correlate with CD8 T-cell impairment and poor survival in hepatocellular carcinoma patients. Gastroenterology 2007;132:2328-39.

76. Foss FM. Immunologic mechanisms of antitumor activity. Semin Oncol 2002;29:5-11.

77. Balkwill F, Mantovani A. Inflammation and cancer: back to Virchow? Lancet 2001;357:539-45.

78. Kaplanski G, Marin V, Montero-Julian F, et al. IL-6: a regulator of the transition from neutrophil to monocyte recruitment during inflammation. Trends Immunol 2003;24:25-9.

79. Dunn GP, Old LJ, Schreiber RD. The immunobiology of cancer immunosurveillance and immunoediting. Immunity 2004;21:137-48.

80. Zitvogel L, Tesniere A, Kroemer G. Cancer despite immunosurveillance: immunoselection and immunosubversion. Nat Rev Immunol 2006;6:715-27.

81. Naito Y, Saito K, Shiiba K, et al. CD8+ T cells infiltrated within cancer cell nests as a prognostic factor in human colorectal cancer. Cancer Res 1998;58:3491-4.

82. Baxevanis CN, Dedoussis GV, Papadopoulos NG, et al. Tumor specific cytolysis by tumor infiltrating lymphocytes in breast cancer. Cancer 1994;74:1275-82.

83. Pagès F, Berger A, Camus M, et al. Effector memory T cells, early metastasis, and survival in colorectal cancer. N Engl J Med 2005;353:2654-66.

84. Galon J, Costes A, Sanchez-Cabo F, et al. Type, density, and location of immune cells within human colorectal tumors predict clinical outcome. Science 2006;313: 1960-4.

85. Galon J, Fridman WH, Pagès F. The adaptive immunologic microenvironment in colorectal cancer: a novel perspective. Cancer Res 2007;67:1883-6.

86. Wada Y, Nakashima O, Kutami R, et al. Clinicopathological study on hepatocellular carcinoma with lymphocytic infiltration. Hepatology 1998;27:407-14.

87. Chavan SS, Chiplunkar SV. Immunophenotypes and cytotoxic functions of lymphocytes in patients with hepatocellular carcinoma. Tumori 1997;83:762-7.

88. Piccirillo CA. Regulatory T cells in health and disease. Cytokin. 2008;43:395-401.
89. Sakaguchi S. Naturally arising CD4+ regulatory t cells for immunologic self-tolerance and negative control of immune responses. Annu Rev Immunol 2004;22:531-62.

90. Zhang L, Conejo-Garcia JR, Katsaros D, et al. Intratumoral $\mathrm{T}$ cells, recurrence, and survival in epithelial ovarian cancer. N Engl J Med 2003;348:203-13.

91. Morse MA, Clay TM, Mosca P, Lyerly HK. Immunoregulatory T cells in cancer immunotherapy. Expert Opin Biol Ther 2002;2:827-34.

92. Chouaib S, Asselin-Paturel C, Mami-Chouaib F, et al. The host-tumor immune conflict: from immunosuppression to resistance and destruction. Immunol Today 1997;18:493-7.

93. Whiteside TL. The tumor microenvironment and its role in promoting tumor growth. Oncogene 2008;27: 5904-12.

94. Jonuleit H, Schmitt E, Stassen M, et al. Identification and functional characterization of human CD4(+)CD25(+) T cells with regulatory properties isolated from peripheral blood. J Exp Med 2001;193:1285-94.

95. Levings MK, Sangregorio R, Roncarolo MG. Human $\operatorname{cd} 25(+) \operatorname{cd} 4(+) \mathrm{t}$ regulatory cells suppress naive and memory $\mathrm{T}$ cell proliferation and can be expanded in vitro without loss of function. J Exp Med 2001;193: 1295-302.

96. Godfrey WR, Spoden DJ, Ge YG, et al. Cord blood CD4(+)CD25(+)-derived T regulatory cell lines express FoxP3 protein and manifest potent suppressor function. Blood 2005;105:750-8.

97. Fontenot JD, Gavin MA, Rudensky AY. Foxp3 programs the development and function of CD4+CD25+ regulatory T cells. Nat Immunol 2003;4:330-6.

98. Ghiringhelli F, Ménard C, Terme M, et al. CD4+CD25+ regulatory $\mathrm{T}$ cells inhibit natural killer cell functions in a transforming growth factor-beta-dependent manner. J Exp Med 2005;202:1075-85.

99. Roncarolo MG, Bacchetta R, Bordignon C, et al. Type 1 T regulatory cells. Immunol Rev 2001;182:68-79.

100. Wang J, Ioan-Facsinay A, van der Voort EI, et al. Transient expression of FOXP3 in human activated nonregulatory CD4+ T cells. Eur J Immunol 2007;37:129-38.

101. Gavin MA, Torgerson TR, Houston E, et al. Single-cell analysis of normal and FOXP3-mutant human T cells: FOXP3 expression without regulatory $\mathrm{T}$ cell development. Proc Natl Acad Sci U S A 2006;103:6659-64.

102. Walker MR, Kasprowicz DJ, Gersuk VH, et al. Induction of FoxP3 and acquisition of $\mathrm{T}$ regulatory activity by stimulated human CD4+CD25- T cells. J Clin Invest 2003;112:1437-43.

103. Seddiki N, Santner-Nanan B, Martinson J, et al. Expression of interleukin (IL)-2 and IL-7 receptors discriminates between human regulatory and activated $\mathrm{T}$ cells. J Exp Med 2006;203:1693-700.

104. Liu W, Putnam AL, Xu-Yu Z, et al. CD127 expression inversely correlates with FoxP3 and suppressive function of human $\mathrm{CD} 4+\mathrm{T}$ reg cells. J Exp Med 2006;203:1701-11.

105. Kaech SM, Tan JT, Wherry EJ, et al. Selective expression of the interleukin 7 receptor identifies effector CD8 T cells that give rise to long-lived memory cells. Nat Immunol 2003;4:1191-8.

106. Ormandy LA, Hillemann T, Wedemeyer H, et al. Increased populations of regulatory $\mathrm{T}$ cells in peripheral 
blood of patients with hepatocellular carcinoma. Cancer Res 2005;65:2457-64.

107. Ling KL, Pratap SE, Bates GJ, et al. Increased frequency of regulatory $\mathrm{T}$ cells in peripheral blood and tumour infiltrating lymphocytes in colorectal cancer patients. Cancer Immun 2007;7:7.

108. Liyanage UK, Moore TT, Joo HG, et al. Prevalence of regulatory $\mathrm{T}$ cells is increased in peripheral blood and tumor microenvironment of patients with pancreas or breast adenocarcinoma. J Immunol 2002;169:2756-61.

109. Ichihara F, Kono K, Takahashi A, et al. Increased populations of regulatory $\mathrm{T}$ cells in peripheral blood and tumor-infiltrating lymphocytes in patients with gastric and esophageal cancers. Clin Cancer Res 2003;9: 4404-8.

110. Visser J, Nijman HW, Hoogenboom BN, et al. Frequencies and role of regulatory $\mathrm{T}$ cells in patients with (pre)malignant cervical neoplasia. Clin Exp Immunol 2007;150:199-209.

111. Grauer OM, Nierkens S, Bennink E, et al. $\mathrm{CD} 4+\mathrm{FoxP} 3+$ regulatory $\mathrm{T}$ cells gradually accumulate in gliomas during tumor growth and efficiently suppress antiglioma immune responses in vivo. Int J Cancer 2007;121:95-105.

112. Gupta S, Joshi K, Wig JD, Arora SK. Intratumoral FOXP3 expression in infiltrating breast carcinoma: Its association with clinicopathologic parameters and angiogenesis. Acta Oncol 2007;46:792-7.

113. Liyanage UK, Moore TT, Joo HG, et al. Prevalence of regulatory $\mathrm{T}$ cells is increased in peripheral blood and tumor microenvironment of patients with pancreas or breast adenocarcinoma. J Immunol 2002;169:2756-61.

114. Ikemoto T, Yamaguchi T, Morine Y, et al. Clinical roles of increased populations of Foxp3 $+\mathrm{CD} 4+\mathrm{T}$ cells in peripheral blood from advanced pancreatic cancer patients. Pancreas 2006;33:386-90.

115. Hiraoka N, Onozato K, Kosuge T, Hirohashi S. Prevalence of FOXP3 + regulatory T cells increases during the progression of pancreatic ductal adenocarcinoma and its premalignant lesions. Clin Cancer Res 2006;12:5423-34.
116. Hinz S, Pagerols-Raluy L, Oberg HH, et al. Foxp3 expression in pancreatic carcinoma cells as a novel mechanism of immune evasion in cancer. Cancer Res 2007;67:8344-50.

117. Wysocki CA, Jiang Q, Panoskaltsis-Mortari A, et al. Critical role for CCR5 in the function of donor CD4+CD25+ regulatory $\mathrm{T}$ cells during acute graft-versus-host disease. Blood 2005;106:3300-7.

118. Yurchenko E, Tritt M, Hay V, et al. CCR5-dependent homing of naturally occurring CD4+ regulatory $\mathrm{T}$ cells to sites of Leishmania major infection favors pathogen persistence. J Exp Med 2006;203:2451-60.

119. Mizukami Y, Kono K, Kawaguchi Y, et al. CCL17 and CCL22 chemokines within tumor microenvironment are related to accumulation of Foxp3+ regulatory $\mathrm{T}$ cells in gastric cancer. Int J Cancer 2008;122:2286-93.

120. Iellem A, Mariani M, Lang R, et al. Unique chemotactic response profile and specific expression of chemokine receptors CCR4 and CCR8 by CD4(+)CD25(+) regulatory T cells. J Exp Med 2001;194:847-53.

121. Kallikourdis M, Andersen KG, Welch KA, Betz AG. Alloantigen-enhanced accumulation of CCR5+ 'effector' regulatory $\mathrm{T}$ cells in the gravid uterus. Proc Natl Acad Sci U S A 2007;104:594-9.

122. Hirahara K, Liu L, Clark RA, et al. The majority of human peripheral blood CD4+CD25 highFoxp3+ regulatory $\mathrm{T}$ cells bear functional skin-homing receptors. J Immunol 2006;177:4488-94.

123. Menning A, Höpken UE, Siegmund K, et al. Distinctive role of CCR7 in migration and functional activity of naive- and effector/memory-like Treg subsets. Eur J Immunol 2007;37:1575-83.

124. Kleinewietfeld M, Puentes F, Borsellino G, et al. CCR6 expression defines regulatory effector/memory-like cells within the CD25(+)CD4+ T-cell subset. Blood 2005; 105:2877-86.

125. Tan MC, Goedegebuure PS, Belt BA, et al. Disruption of CCR5-dependent homing of regulatory $\mathrm{T}$ cells inhibits tumor growth in a murine model of pancreatic cancer. J Immunol 2009;182:1746-55. 